\title{
Comprimento da estaca e tipo de substrato na propagação vegetativa de atroveran
}

\author{
Shoot cutting length and substrate types on vegetative propagation of atroveran
}

\author{
Larissa Corrêa do Bomfim Costa ${ }^{\mathrm{I}}$ José Eduardo Brasil Pereira Pinto ${ }^{\mathrm{II}}$ \\ Suzan Kelly Vilela Bertolucci ${ }^{I}$
}

\begin{abstract}
- NOTA -
RESUMO

A propagação vegetativa de espécies medicinais vem despertando interesse das pesquisas agronômicas, uma vez que se constitui no ponto de partida e em ferramenta básica para qualquer cultivo em escala comercial. Este trabalho objetivou determinar o comprimento de estaca e o tipo de substrato mais adequados para a propagação vegetativa de atroveran. Em condições de casa de vegetação sob nebulização intermitente, foram testados dois comprimentos de estacas (10 e $20 \mathrm{~cm}$ ) e três substratos (areia lavada, casca de arroz carbonizada e substrato comercial Plantmax $\left.{ }^{\circledR}\right)$, em delineamento experimental em blocos casualizados, com quatro repetições e cinco estacas por parcela. Aos trinta e cinco dias, foram avaliados a porcentagem de enraizamento, o comprimento da maior raiz (cm) e a biomassa seca das folhas e das raízes $(\mathrm{mg})$. Os resultados indicaram que a propagação vegetativa de atroveran por meio de estaquia é viável, uma vez que o seu enraizamento médio ficou acima de $70 \%$. As mudas de atroveran obtidas de estacas com $20 \mathrm{~cm}$ apresentaram maior biomassa seca das folhas e das raízes,

point and a basic tool for any cultivation in commercial scale. The objective of this work was to determine the best shoot cutting length and the best substrate for vegetative propagation of Ocimum selloi. Cuttings were placed in greenhouse conditions under intermittent mist. Two cutting sizes (10 and 20cm) and three substrate types (washed sand, carbonized rice hulls and commercial substrate Plantmax ${ }^{\circledR}$ ) were tested. The experiment was in blocks randomly distributed in four replications and five cuttings for parcel. After thirty five days the percentage of rooting, the length of the bigger root $(\mathrm{cm})$ and the leaf and root dry weight $(\mathrm{mg})$ were analysed. The results indicated that the vegetative propagation of Ocimum selloi by cuttings is viable, once its mean rooting was over $70 \%$. It was not observed significative interaction within the adopted treatments. The cuttings with $20 \mathrm{~cm}$ length presented larger leaf and root dry weight but the percentage of rooting and the length of the bigger root was not affected by the cutting lenght. The substrate types did not present effect on the development of the cuttings. The production of Ocimum selloi seedlings is recommended with $20 \mathrm{~cm}$ length cuttings using any substrate tested.
\end{abstract} apesar de o comprimento da estaca não ter afetado a porcentagem de enraizamento e o comprimento da raiz. Os tipos de substrato não proporcionaram efeito sobre o desenvolvimento das estacas de atroveran. Recomenda-se a produção de mudas de atroveran com estacas de $20 \mathrm{~cm}$ de comprimento, utilizando-se qualquer um dos três substratos testados.

Palavras-chave: Ocimum selloi (Benth), planta medicinal, estaquia.

\section{ABSTRACT}

The vegetative propagation of medicinal species is in increasing agronomic interest because it is the starting
Key words: Ocimum selloi Benth., medicinal plant, cutting.

Ocimum selloi Benth. é um subarbusto perene, pertencente à família Lamiaceae, nativo das regiões Sul e Sudeste do Brasil, que pode ser multiplicado por sementes ou estacas. A espécie conhecida popularmente como elixir-paregórico nos Estados da Bahia, do Espírito Santo e Rio de Janeiro, como alfavaquinha em Minas Gerais e como atroveran em São Paulo, possui largo uso popular, como

\footnotetext{
'Departamento de Ciências Biológicas (DCB), Universidade Estadual de Santa Cruz (UESC), 45662-000, Ilhéus, BA, Brasil. E-mail: larissacbc@uol.com.br. Autor para correspondência.

"Departamento de Agricultura (DAG), Universidade Federal de Lavras (UFLA), CP 37, 37200-000, Lavras, MG, Brasil.
} 
antidiarréico, antiespasmódico e antiinflamatório, além de já ter a sua atividade comprovada como repelente de insetos. Apesar de ser uma fonte potencial de estragol e metileugenol, ainda não foi explorada comercialmente, sendo encontrada apenas na forma silvestre ou cultivada em quintais domésticos.

Trabalhos de domesticação de plantas medicinais são escassos ou inexistentes para a maioria das espécies, sendo necessário o desenvolvimento de estudos relacionados à adaptação destas plantas às condições de cultivo, principalmente em virtude do aumento da demanda por parte das indústrias farmacêutica e cosmética. Mesmo que a planta possa ser propagada sexualmente, a propagação vegetativa tem inúmeras vantagens por ser uma técnica simples, rápida e barata, produzir muitas mudas em espaço reduzido com maior uniformidade do estande e manter as características genéticas da planta doadora (HARTMANN \& KESTER, 1981).

Considerando que o objetivo principal na produção de plantas medicinais é a obtenção de matéria-prima em quantidade e qualidade desejadas, deve-se tentar diminuir a interferência dos fatores ambientais, técnicos e da variabilidade química natural das espécies. Estudos de caracterização química do óleo essencial de atroveran registraram variações nos teores e na composição dos seus constituintes majoritários, que podem se apresentar como metil chavicol, metil eugenol (MARTINS et al., 1997) e transanetol com metil chavicol (MORAES et al., 2002), comprovando a existência de diferentes quimiotipos nesta espécie. A propagação vegetativa é uma importante ferramenta no melhoramento de espécies lenhosas e herbáceas e vem sendo amplamente utilizada, visando a melhorar e manter variedades de importância econômica e medicinal (EHLERT et al., 2004). Salienta-se que, após a seleção da cultivar de maior interesse, a propagação vegetativa permite estabelecer plantios uniformes, mantendo o valor agronômico da cultivar.

O interesse da pesquisa na propagação vegetativa de plantas medicinais é bastante recente e tem-se concentrado na verificação dos melhores tipos e comprimentos de estaca, no efeito do uso de reguladores de crescimento e nos substratos mais adequados para o enraizamento. Nesse sentido, algumas das principais espécies já estudadas foram: Solidago chilensis (CORREIA, 1998), Cissus sicyoides (ABREU et al., 2003), Lippia alba (BIASI \& COSTA, 2003), Ocimum gratissimum (EHLERT et al., 2004) e Baccharis articulata, Baccharis trimera e Baccharis stenocephala (BONA et al., 2005a e 2005b).
Este trabalho teve como objetivo avaliar o comprimento de estaca e o tipo de substrato mais adequados para a propagação vegetativa de atroveran.

Em outubro de 2005, foram coletadas estacas herbáceas, sem folhas, de dois comprimentos (10 e $20 \mathrm{~cm}$ ) da porção apical de plantas matrizes com um ano de idade cultivadas no Horto de Plantas Medicinais da Universidade Federal de Lavras (UFLA). Estas foram plantadas em bandejas de poliestireno expandido com 72 células, em três tipos de substratos (areia lavada, casca de arroz carbonizada e substrato comercial Plantmax ${ }^{\circledR}$ ) e mantidas em casa de vegetação sob nebulização intermitente.

Após 35 dias de cultivo, as estacas foram colhidas e levadas ao Laboratório de Cultura de Tecidos Vegetais e Plantas Medicinais (DAG/UFLA) para separação das folhas e do sistema radicular. Esse material foi embalado individualmente, em sacos de papel kraft, e secados em estufa com circulação de ar forçada a $70^{\circ} \mathrm{C}$, até massa constante. As variáveis analisadas foram: enraizamento (número de estacas que formaram pelo menos uma raiz visível, expresso em porcentagem), comprimento da maior raiz $(\mathrm{cm})$, biomassa seca (mg) das folhas e das raízes.

O delineamento experimental adotado foi de blocos casualizados, em esquema fatorial (2X3), em quatro repetições, com cinco estacas por parcela, totalizando 120 estacas.

Os resultados obtidos foram submetidos à análise de variância, utilizando-se comparação de médias por meio do teste $\mathrm{F}$ a $5 \%$ de probabilidade para o comprimento de estaca e do teste de Tukey a 5\% de probabilidade para os substratos.

Não foi observada interação significativa entre os tratamentos, mas, de uma forma geral, verificouse que as estacas de atroveran enraizaram com facilidade (Tabela 1$)$.

Apesar de o comprimento da estaca não ter afetado a porcentagem de enraizamento e o comprimento da raiz, as mudas obtidas de estacas com $20 \mathrm{~cm}$ apresentaram maior biomassa seca de folhas e raízes (Tabela 1), o que é interessante, pois mudas mais vigorosas representam melhores chances de estabelecimento da planta no campo. A resposta do comprimento da estaca no enraizamento e no desenvolvimento da muda pode ser muito variável de acordo com a espécie. Em Cissus sicyoides, estacas com 10 e $20 \mathrm{~cm}$ de comprimento não apresentaram diferenças em relação ao número e comprimento das raízes (ABREU et al., 2003), e a variação no comprimento das estacas de Pfaffia glomerata também não afetou a porcentagem de enraizamento e a produção de massa seca de folhas e raízes (NICOLOSO et al., 2001). Por 
Tabela 1 - Efeito do comprimento da estaca e do tipo de substrato nas médias de enraizamento, comprimento da maior raiz, biomassa seca das folhas (BSF) e biomassa seca das raízes (BSR), em estacas de atroveran.

\begin{tabular}{lcccc}
\hline Comprimento da estaca (cm) & Enraizamento (\%) & Comprimento raiz (cm) & BSF (mg) & BSR (mg) \\
\hline 10 & $70,0 \mathrm{a}$ & $7,24 \mathrm{a}$ & $42,9 \mathrm{~b}$ & $11,5 \mathrm{~b}$ \\
20 & $75,0 \mathrm{a}$ & $6,78 \mathrm{a}$ & $91,6 \mathrm{a}$ & $19,7 \mathrm{a}$ \\
& & & & 6,74 \\
DMS & 14,76 & 1,18 & 27,78 & \\
& & & & $13,4 \mathrm{a}$ \\
Substrato & & & $60,0 \mathrm{a}$ & $13,1 \mathrm{a}$ \\
Areia $^{2}$ & $67,5 \mathrm{a}$ & $6,42 \mathrm{a}$ & $74,6 \mathrm{a}$ & $20,3 \mathrm{a}$ \\
Plantmax $^{\circledR}$ & $70,0 \mathrm{a}$ & $6,77 \mathrm{a}$ & $67,0 \mathrm{a}$ & 10,07 \\
Casca Arroz & $80,0 \mathrm{a}$ & $7,83 \mathrm{a}$ & & 49,60 \\
DMS & & & 41,47 & 47,47 \\
CV(\%) & 22,04 & 1,76 & & \\
\hline
\end{tabular}

${ }^{1}$ Médias seguidas por letras distintas diferem significativamente entre si pelo teste $\mathrm{F}$ a $5 \%$ de probabilidade.

${ }^{2}$ Médias seguidas por letras distintas diferem significativamente entre si pelo teste Tukey a 5\% de probabilidade.

outro lado, na estaquia lenhosa de Lippia alba (BIASI \& COSTA, 2003) e de Vernonia condensata (ALMEIDA FILHO et al., 2000), o aumento do comprimento da estaca proporcionou um aumento linear em todas as variáveis analisadas, resposta atribuída provavelmente à maior quantidade de reservas presentes nas estacas maiores.

Os tipos de substrato testados não proporcionaram efeito sobre o desenvolvimento das estacas de atroveran (Tabela 1), ao contrário dos resultados obtidos por BURGOS et al. (2004) com esta mesma espécie, cujo enraizamento e brotação inicial das estacas foram favorecidos pelo uso de substrato inerte (perlita-vermiculita), em contraposição ao uso de terra. Para HARTMAN \& KESTER (1981), o meio de enraizamento ideal deve proporcionar porosidade suficiente para permitir uma boa aeração, ter alta capacidade para retenção de água e, não obstante, uma boa drenagem. Deve-se acrescentar que o substrato pode ser um fator determinante para o sucesso no enraizamento de estacas em muitas espécies (COUVILLON, 1988), embora para outras não tenha qualquer efeito. No caso de Solidago chilensis, os tipos de substrato não influenciaram a biomassa seca foliar, mas afetaram significativamente a biomassa seca das raízes (CORREIA, 1998). Estacas de Baccharis articulata e Baccharis stenocephala também tiveram o seu enraizamento influenciado pelo tipo de substrato (BONA et al., 2005a). Por outro lado, pesquisas recentes com propagação vegetativa de outras espécies medicinais como Ocimum gratissimum (EHLERT et al., 2004), Lippia alba (BIASI \& COSTA, 2003), Baccharis trimera (BONA et al., 2005a) e Ageratum conyzoides (MOMENTÉ et al., 2002) não encontraram diferenças significativas no enraizamento com os substratos testados, o que demonstra maior capacidade de adaptação às diferentes condições físicas e químicas dos substratos (BONA et al., 2005a) e permite a escolha do substrato mais acessível para a propagação vegetativa dessas espécies.

A propagação vegetativa de atroveran por meio de estaquia é promissora, uma vez que a porcentagem média de enraizamento das estacas com 10 e $20 \mathrm{~cm}$ de comprimento está acima de $70 \%$. Recomenda-se a produção de mudas de atroveran com estacas de $20 \mathrm{~cm}$ de comprimento, utilizando-se qualquer um dos três substratos testados.

\section{REFERÊNCIAS}

ABREU, I.N. et al. Propagação in vivo e in vitro de Cissus sicyoides, uma planta medicinal. Acta Amazônica, Manaus, v.33, n.1, p.1-7, 2003.

ALMEIDA FILHO, L.A. et al. Comprimento de estaca de aluman para propagação vegetativa. In: SIMPÓSIO LATINOAMERICANO DE PLANTAS MEDICINAIS, AROMÁTICA E CONDIMENTARES, 2000, São Pedro, SP. Trabalhos apresentados e palestras. Horticultura Brasileira. Brasília: SOB/FCAV-UNESP, 2000. V.18, p.986987. Suplemento.

BIASI, L.A.; COSTA, G. Propagação vegetativa de Lippia alba. Ciência Rural, Santa Maria, v.33, n.3, p.455-459, 2003.

BONA, C.M. et al. Estaquia de três espécies de Baccharis. Ciência Rural, Santa Maria, v.35, n.1, p.223-226, 2005 a.

BONA, C.M. et al. Propagação por estaquia de Baccharis articulata (Lam.) Pers., Baccharis trimera (Less.) A.P. de Candolle e Baccharis stenocephala Baker com uso de auxinas. Revista Brasileira de Plantas Medicinais, Botucatu, v.7, n.2, p.26-31, 2005b. 
BURGOS, A.M.L. et al. Propagación del anís de campo Ocimum selloi (Lamiaceae) por medio de esquejes. In: COMUNICACIONES CIENTÍFICAS Y TECNOLÓGICAS, Resumos... Corrientes: Universidad Nacional del Nordeste, 2004. Capturado em 28 jun. 2006. Online. Disponível na Internet http://www.unne.edu.ar/Web/cyt/com2004/5-Agrarias/A-031.pdf.

CORREIA, E. Aspectos da propagação sexuada e vegetativa da arnica brasileira (Solidago chilensis Meyen - ASTERACEAE). In: MING, L.C. et al. Plantas medicinais, aromáticas e condimentares: avanços na pesquisa agronômica. Botucatu: UNESP, 1998. V.2, p.193-208.

COUVILLON, G.A. Rooting response to different treatments. Acta Horticulturae, Leuven, v.277, p.187-196, 1988.

EHLERT, P.A.D. et al. Propagação vegetativa da alfavacacravo utilizando diferentes tipos de estacas e substratos. Horticultura Brasileira, Brasília, v.22, n.1, p.10-13, 2004.
HARTMANN, H.T; KESTER, D.E. Propagación de plantas: princípios e práticas. México: CECSA, 1981. p.237-346.

MARTINS, E.R. et al. Essential oil in the taxonomy of Ocimum selloi Benth. Journal of the Brazilian Chemical Society, Campinas, v.8, n.1, p.29-32, 1997.

MORAES, L.A.S. et al. Phytochemical characterization of essential oil from Ocimum selloi. Anais da Academia Brasileira de Ciências, Rio de Janeiro, v.74, n.1, p.183186, 2002.

MOMENTÉ, V.G. et al. Propagação vegetativa por estaquia de mentrasto em diferentes substratos. Revista Ciência Agronômica, Fortaleza, v.33, n.2, p.5-12, 2002.

NICOLOSO, F.T. et al. Comprimento da estaca de ramo no enraizamento de gingseng brasileiro (Pfaffia glomerata). Ciência Rural, Santa Maria, v.31, n.1, p.57-60, 2001. 